\title{
Students' Perception of Library Services in Academia: A Case Study of Universiti Teknologi Brunei
}

\author{
Thulasimani Munohsamy* \\ Lecturer, Center for Communication, Teaching and Learning,Universiti Teknologi Brunei, Brunei Darussalam
}

\begin{tabular}{l} 
A R T I C L E I N F O \\
\hline Article history: \\
Received:11 October, 2016 \\
Accepted: 21 November 2016 \\
Online: 25 December 2016
\end{tabular}

Keywords:

Library services

Perception

Digital library

Traditional library

Students

\begin{abstract}
A B S T R A C T
This paper is an outcome of a case study conducted at the Universiti Teknologi Brunei in order to measure students' perceptions of the library services offered in the university library. The main objectives were to identify the purpose of the library visit and to find out the service quality of university library, to determine whether digital libraries can replace traditional libraries and to explore if there is correlation between the frequency of the students visit to the library with the service quality provided and also the collection of materials in the library. A total of 142 students were randomly selected from the institution for the purpose of the study. Questionnaire was used as the main instrument for gathering data. The findings of the study shows that $40 \%$ of the students visit the library on weekly basis and $78 \%$ of the students visit the library to study and $70 \%$ of the students visit the library for group discussion. In terms of the service quality, the study reveals that $79 \%$ of the students rated the service as good, very good and excellent. The study also reveals that $46 \%$ of the students rated the collection of materials in the library is average and $40 \%$ of the students rated them as good. Majority of the students (54\%) reported that digital library can replace the traditional libraries. The analysis shows that there is no correlation and relationship between the visit of the students to the library and the service quality and the collections of materials in the library. The students recommended only to vary the genre of books available in the library.
\end{abstract}

\section{Introduction}

A university library is a backbone for any universities that is built in order to achieve the primary goal of teaching and learning, research and community services. A university library is also described as the heart of the universities learning community, providing place for students, lecturers and researchers to do their research and advance their knowledge. Every library renders services to its users. The library has to collect materials, published, non-published, print and non-print, in some depth and globally in almost all the fields of knowledge. University libraries stock thousands of information resources both books, journals and other types of materials and provide access to them [1].

According to [2], the basic functions of any university is to conserve the existing knowledge, to transmit knowledge through teaching and to create new knowledge through research. The university library is the university's principal instrument in the conservation of knowledge through its rational, systematic and

${ }^{*}$ Corresponding Author: Thulasimani Munohsamy, Center for Communication, Teaching and Learning,Universiti Teknologi Brunei, Brunei Darussalam,

+6738934726,ggthulasi@yahoo.co.in comprehensive acquisition of all type of human communications records, publish and unpublished, written or oral in recorded form that embody the ideas of knowledge of past since each new idea or invention grows out of accumulated and conserved knowledge [1].

However, with the emphasis being placed on electronic resources in this present age, the learning community are more interested in the virtual information services on the internet. Therefore, academic libraries need to access the quality of the services and how users' satisfaction can be improved. Furthermore, advocates of technology believe that the Internet removes time and geographic constraints. The development of digital technology brings both opportunities and challenges to academic library [3]. In another word this research is conducted with the intention to further improve the library services based on their major clients, the students' perception on their needs to have a more conducive study environment and knowledge storage.

The Universiti Teknologi Brunei's (UTB) library measures an area of 3850 sq meters, situated at the crossing of all the central services with an 'under one roof' concept. Currently this library caters for 2300 undergraduates and postgraduates and around 145 faculty members. In order to maintain the users' needs and 
satisfactions of the library services, this research is conducted with the objective to further improve the library services.

\section{Objective of the study}

The objective of this research is to:

1. To find out the frequency of students' visit to UTB library.

2. To identify the purpose of the library visited by the students.

3. To study the service quality of the UTB library.

4. To find out whether digital libraries can replace the traditional libraries.

5. To find out if there is correlation between the service quality of UTB library and the students visit to the library.

6. To find out if there is correlation between the book collections and materials in UTB library and the students visit to the library.

\section{Scope of the study}

This study covers the perceptions of UTB students on the library services in order to find out how services can be improved for the betterment of the students.

\section{Significance of the study}

This study investigates the perception of the students on the Universiti Teknologi Brunei (UTB) library services. The findings of this study can be helpful and benefit students, librarians, library and the university management. For the librarians, university and library management, it can help to change policies and improve the service quality of the library which will directly benefit the students where they can have better service delivery which can encourage them to visit and benefit from the library often.

This finding also is expected to contribute to the existing literature in the field of the perception of the students on library services in UTB and serve as a basis for future research in this area.

\section{Literature Review}

In this section the studies related to this research is discussed. Many related studies have been conducted on library services all around the world. According to [4], the library engages the users in activities intended to make them critical thinkers, problem solvers, independent information seekers and lifelong learners. The library teaches the library users how to access, store, retrieve and use information. Users are also taught how to carry out crossreferencing to access information and cite bibliographies for proper referencing.

Furthermore, [5], conducted a study on 310 students in College of Industrial Management Fahd University of Petroleum and Minerals. The results show that the 'contact personnel' is the most influencing issue in the evaluation of service quality. However, other aspects that significantly contributed to the findings are, classroom, building, lightening and overall cleanliness.

In another study conducted by [6] among 350 students from different universities on student satisfaction in higher education showed that librarians' expertise is the most influential factor on the students' satisfaction whereas courses conducted and learning environment are the next vital factors.

Meanwhile [7], conducted a study in the University of Rajshahi to measure the perception and satisfaction level of undergraduate and master's students of library services. The findings show that more than $42 \%$ of the students visit the library for exam preparation and the study also revealed that the service quality of the library is associated with the preference of study places and collections of the library and $74 \%$ of the respondents reported that digital library can replace traditional libraries.

Furthermore, [1] also conducted a study on students' perception of library services in Universities in Benue State. Questionnaires were distributed to 200 students randomly. The study reveals that the students in that universities have a negative perception on the library services. This was because lack of awareness by the students on how to search for information materials and ignorance on information search strategies. The study also found that students were frustrated with the outdated material and the services provided was not encouraging.

Besides that, another study conducted among 60 accounting students in Nigeria on their perceptions of the relevance of library in the $21^{\text {st }}$ century found that the relevance of a library to the society cannot diminish even in the years to come, hence all the respondents indicated that the library has impacted the lives of students, researchers, businessmen and women and continue to impact future generations [8].

These are some of the similar studies done by other researchers in this area. The similarity or differences between the findings in the literature and this study will be discussed later in the paper. In the next section, the research method is discussed.

\section{Methodology}

This is a quantitative study and the sample of study consisted of 142 Universiti Teknologi Brunei students. The study sample consisted of 71 male students and 71 female students. The data collection was done through the use of an established survey questionnaire with five point Likert scale to capture students' responses. The questionnaire consisted of 3 demographic questions, four questions which cover the students' perception of library services in UTB and two open-ended questions on whether digital library can replace the traditional library and the students' recommendation to improve the library services in UTB. The collected data were analyzed using SPSS 20.0 software (Statistical Packages for Social Sciences) and presented in the form of frequency and percentage. These are the methods used for this study. The results and discussion are explained in the following section. 


\section{Results and Discussion}

The main purpose of this study is to investigate the Universiti Teknologi Brunei students' perception of the library services at the university. A total of 142 student randomly picked from the Faculty of Engineering and the School of Computing and Informatics participated in the study. $50 \%$ of the respondents were male and another $50 \%$ of the respondents were female. The data analyzed are discussed as follows. Figure 1 below shows the educational status of the respondents. Among the respondents, 58 students (41\%) were first year students, 26 second year students (18\%), 8 third year students $(6 \%)$ and 50 final year students (35\%).

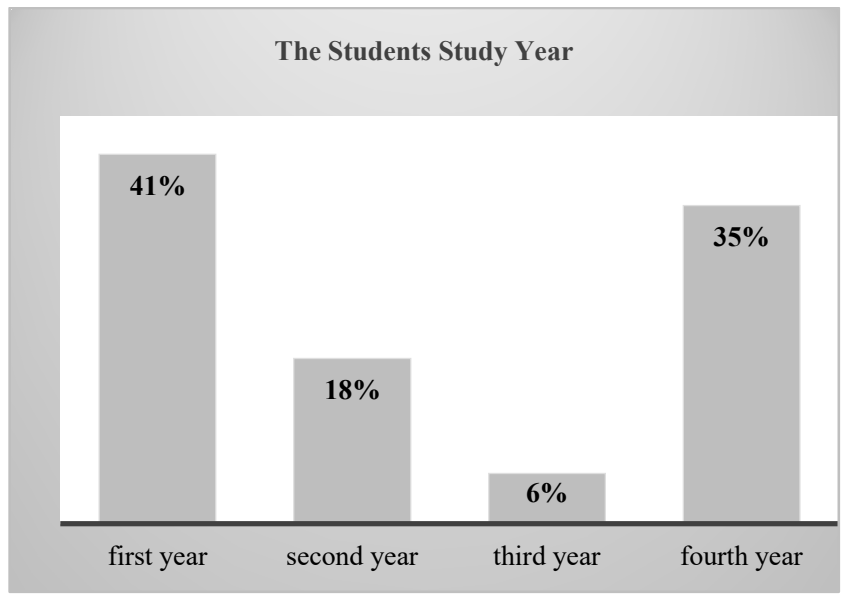

Figure 1: The students' study year

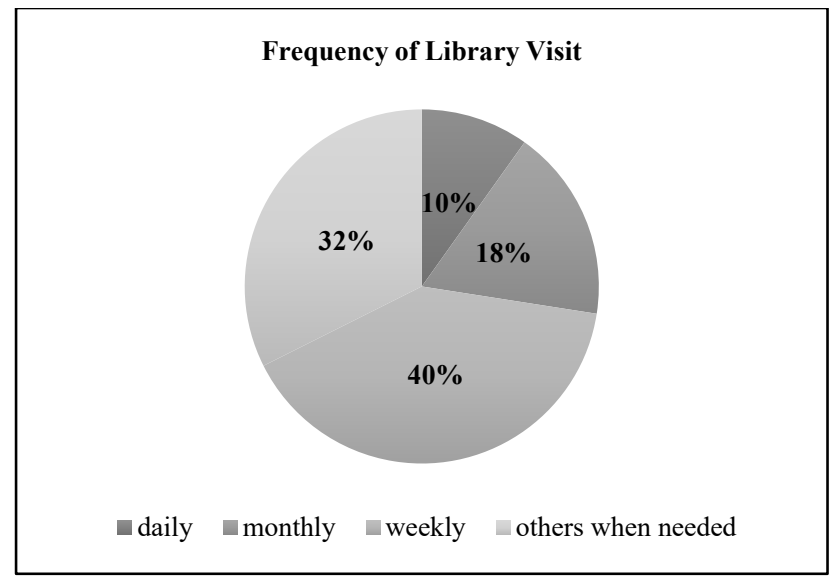

Figure 2: Frequency of Library Visit

The frequency of library visit by the users to UTB library is presented in the Figure 2 above. It denotes that $10 \%$ of the users visit the library every day, $40 \%$ of the users' visits on weekly basis, $18 \%$ of the users visit monthly basis and the remaining $32 \%$ of the users visit the library when it is necessary to find materials in the library.

Figure 3 above shows the results of the students' purpose of their visit to the library. The result exhibits that $59 \%$ of the students visit the library for exam preparation, $19 \%$ of the students visit to look for journal publications, $78 \%$ of the students visit to study and $70 \%$ of the students visit for group discussions.

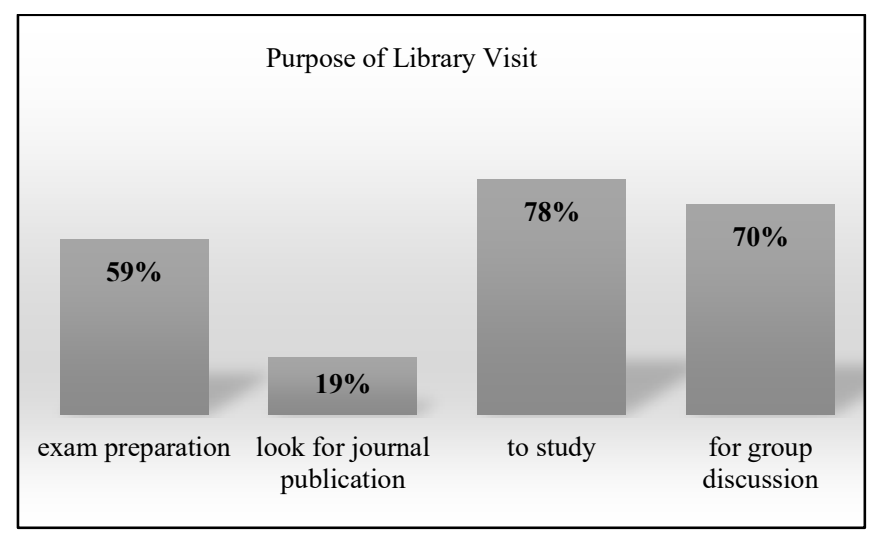

Figure 3: Purpose of Library Visit

The figure 4 above shows the service quality of the university library. Majority of the students rated the library services as good, very good and excellent (79\%). A total of $20 \%$ of the students rated the library services as average and only $1 \%$ rated the service as poor.

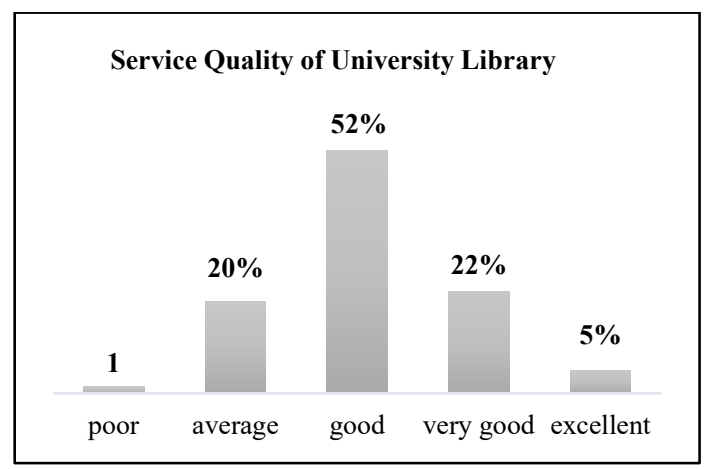

Figure 4: Service Quality of University Library

Figure 5 below shows students' comments on the collections of the library. A total of $46 \%$ of the students claimed the collection of materials are average, $40 \%$ of the students said that the collection was good and $10 \%$ of the students said it was very good. $2 \%$ of the students said it was excellent collection and the remaining $2 \%$ of the students said it was poor.

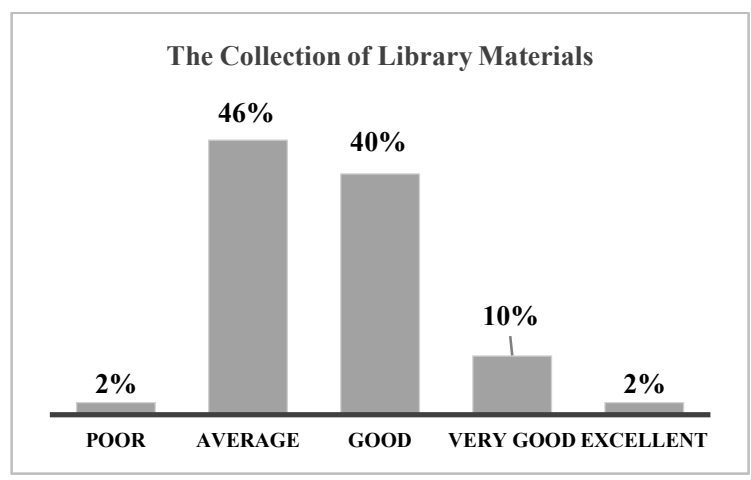

Figure 5: The Collection of Library Materials 
Figure 6 below shows the percentage of students who thinks that digital library can replace traditional library. A majority of the students (54\%) answered yes and the remaining $46 \%$ said no to this question. The majority of the students said yes because they think that it is easier and more convenient to access the internet with no time limitation and geographical boundaries. This results is similar to the study done by [7], as the results show that $74 \%$ of the students believe that digital library can replace the traditional library. However, the result of this study supports the study done in Nigeria in the year 2013 where $60 \%$ of the students said that traditional library can never be replaced as it has impacted the users [8].

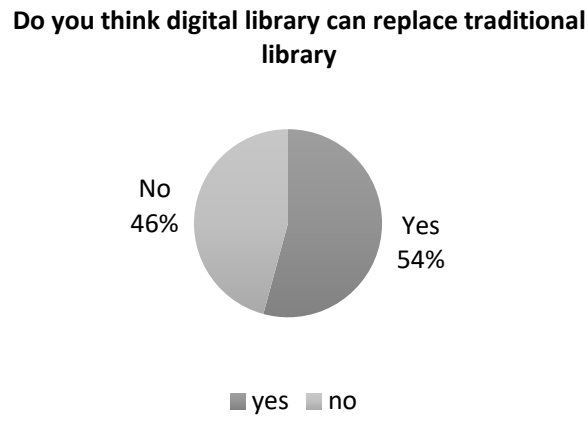

Figure 6: Do you think digital library can replace traditional library?

Furthermore, the data analysis using Pearson correlation on whether there is a correlation between the students visit to the library and the service quality of UTB library, shows that there is no correlation as the correlation shows -0.003 with the significance ( 2 tailed) by 0.969 . There is also no relationship between the students' visit to the library and the collection of materials available in the library as the Pearson correlation shows 0.121 with significance ( 2 tailed) by 0.153 . These are the results obtained from the study. The conclusion will be discussed in the following section.

The students also suggested to update the collection of books and to have a variety of genres including novels for their reading pleasure. Some students suggested to have more computers in the library for students use and also provide printing services. A minority of the students suggested to open the 24/7 room on Fridays and Sundays so that they can use the room to study.

\section{Conclusion}

The purpose of this research was to study the students' perception of library services in Universiti Teknologi Brunei. The study shows that $79 \%$ of the students are happy with the services in the library. The students' recommendation would be only to improve the locker system and to have more books in different genres. Since the survey is only done with 142 students, it cannot be generalized to any other subset of population. This study was also designed to present a preliminary investigation of the understanding of how educational institutional library is providing library services. The sample was not large enough to depict rigid conclusion but however gives suggestions for further studies. Some of the recommendation suggested by the students are discussed in the following section.

\section{Acknowledgement}

I would like to thank the UTB library for giving me the opportunity to conduct the research and Sures Muniandy for being the inspiration and guide for writing the paper.

\section{References}

[1] D. Ashaver, M. D. Bem Bura, "Students' Perception of library Services in Universities in Benue State" IOSR Journal of Research \& Method in Education, 1(5): 41-48, 2013.

[2] Aguolu, I.E. Aguolu, "Libraries and Information management in Nigeria: Seminal essays on themes and problems Maiduguri", Nigeria: Ed-linform Services (2002).

[3] K. H. Maxwell, R. G. Cunmings, S. W. Wang, "Business Students' Perception of University Library Service Quality and Satisfaction", Contemporary Issues in Education Research-Second Quarter, 7(2): 137-144 (2014).

[4] N.G. Somi, K. De Jager, "The Role of Academic Libraries in the Enhancement of Information Literacy: A study of Fort Hare Library”, South African Journal of Library and Information Science, 259-266 (2005).

[5] M.S. Sohail, N.M. Shaikh, "Quest for Excellence in Business Education: A Study of Student impression of Service Quality", The International Journal of Education Management, 8(1): 58-66 (2004).

[6] B.Z. Butt, K. Rehman, "A Study Examining the Students Satisfaction in Higher Education"' Procedia Social and Behavioural Sciences, 2(2): 5446-50 (2010).

[7] S. K. M. Mostofa, Md. U. Hossain, "Students' Perceptions of Library Services in Academia of Bangladesh: A Case study of Rajshahi University", International Journal of Research in Humanities, Arts \& Literature, 2(8): 8190 (2014)

[8] S. U. Omeluzor, I. A. Bamidele, C. C. Ukangwa, H. U. Amadi, "The relevance of a library in the $21^{\text {st }}$ century: Students' perception", International Journal of Library and Information Science, 5(6): 160-166 (2013). 